\title{
Multiple Environmental Variables Affect Germination and Mortality of an Annual Salt Marsh Pioneer: Salicornia procumbens
}

\author{
M. van Regteren ${ }^{1,2} \cdot$ E. H. Meesters ${ }^{1,2} \cdot$ M. J. Baptist ${ }^{1,2} \cdot$ A. V. de Groot ${ }^{1} \cdot$ T. J. Bouma ${ }^{3,4} \cdot$ K. Elschot $^{1}$
}

Received: 2 December 2019/Revised: 16 March 2020 / Accepted: 18 March 2020 / Published online: 19 April 2020

(C) The Author(s) 2020

\begin{abstract}
Salt marshes, providing numerous ecosystem services, are degrading worldwide. To effectively aid conservation and restoration efforts, increased knowledge on marsh expansion processes and the initial establishment of pioneer vegetation is essential. In this study, we disentangle environmental drivers that affect the lifecycle of the annual pioneer Salicornia procumbens at the salt marsh edge. We studied the effect of various environmental variables on the start of germination, germination success and mortality before seed-set in a field experiment in the Dutch Wadden Sea at Westhoek. Our results indicate that temperature and sedimentation inhibited the initiation of germination. Once germination occurred, higher precipitation rates increased germination success. In contrast, sedimentation rates above $0.5 \mathrm{~mm}$ day $^{-1}$ halved germination success through burial of freshly sprouted seedlings. Unexpectedly, natural germination was low, indicating that seed availability may have been limited, despite a seed source nearby. Frequent inundation, extended periods without inundation (through desiccation of the soil) and a highly dynamic bed level increased mortality before seed-set. Consequently, bed-level dynamics (erosion, sedimentation and bed-level variation) impact seed production dually (decrease germination and increase mortality) and thus potentially reproduction success. A high seed reproduction is crucial for annuals, such as S. procumbens, to re-establish the following year. Next to advancing our general knowledge of natural salt marsh expansion, results in this study can also be used to assess the potential of a given site for salt marsh stimulation or restoration. Seed availability and local bedlevel dynamics are key in the successful establishment of a salt marsh pioneer: Salicornia procumbens.
\end{abstract}

Keywords Salt marsh $\cdot$ Annual $\cdot$ Sediment dynamics $\cdot$ Intertidal flat $\cdot$ Inundation regime $\cdot$ Seedling recruitment

\section{Introduction}

Salt marshes and intertidal flats are essential parts of coastal systems that provide protection against floods through wave attenuation (Schuerch et al. 2014; Temmerman et al. 2013). They are vital habitats for migratory and breeding birds and

Communicated by Charles T Roman

M. van Regteren

marin.vanregteren@wur.nl

1 Wageningen Marine Research, Wageningen University and Research, 1781 AG Den Helder, The Netherlands

2 Aquatic Ecology and Water Quality Management, Wageningen University and Research, 6700 AA Wageningen, The Netherlands

3 Department of Estuarine and Delta systems, Royal Netherlands Institute for Sea Research (NIOZ), 4400

AC Yerseke, The Netherlands

4 Utrecht University, 3508, TC Utrecht, The Netherlands are host to a variety of unique floral and faunal communities (Reise et al. 2010). Currently, many salt marshes are degrading due to human-driven change, such as embankment, pollution, and alterations to coastal hydrology and morphology (Gedan et al. 2009). Therefore, increasing our knowledge on natural marsh expansion as well as restoration is imperative. Most studies focus on the vertical accretion rates of salt marshes and their ability to keep up with sea level rise (Kirwan et al. 2016; Stoddart et al. 1989; Temmerman et al. 2013). Equally, or maybe even more important, are the processes that drive the lateral, seaward development of salt marshes (Bouma et al. 2016; Cao et al. 2018); especially in areas where landward migration of marsh area is constrained by hard infrastructure such as dikes (Elias et al. 2012). Fieldverified environmental limitations to successful initial establishment of pioneer vegetation in bare tidal flats need to be identified (Bouma et al. 2014). This is specifically relevant in the sparsely vegetated transition zone of two adjacent systems (un-vegetated intertidal flat and vegetated pioneer zone), which is the prime location for seaward salt marsh expansion. 
Crucial for marsh stability and expansion as well as marsh restoration is the successful establishment of pioneer vegetation in the transition zone (Olff et al. 1997; Zedler et al. 2003). In case of annual plants, this requires a seed source in proximity, either from adult plants or from a local seed bank (Rand 2000). Salt marsh seeds and seedlings need to be able to germinate and survive in a dynamic environment. In earlier studies, the effect of one or two particular parameters on germination and survival of intertidal pioneer vegetation was often studied in laboratory experiments: including sediment dynamics (Boorman et al. 2001; Cao et al. 2018), inundation regime (Boorman et al. 2001; Egan and Ungar 2000), salinity (Keiffer et al. 1994), rainfall (Xie et al. 2019), temperature (Khan et al. 2000; Ungar 1967), and/or bioturbation (van Regteren et al. 2017; Zhu et al. 2016). Field experiments are much scarcer, but are important as they can provide valuable information on realistic combinations of these environmental parameters. Additionally, most research is restricted to the germination phase of pioneer plants (Carter and Ungar 2003; ElseyQuirk et al. 2009; Khan et al. 2000; Noe and Zedler 2001), whereas understanding seedling establishment and mortality before seed-set is equally important.

The pioneer Salicornia procumbens is a key species in NW-European salt marshes, as it is often the first plant species to colonize the bare tidal flat (Bouma et al. 2014; Davy et al. 2001; Davy et al. 2011). S. procumbens is an annual species that is dependent on seeds for yearly seedling recruitment. It has an important role in its environment: firstly, the species affect faunal assemblages (van der Wal and Herman 2012). Further, it facilitates the subsequent establishment of other perennial salt marsh plants (Hacker and Bertness 1999; Langlois et al. 2001; Smit van der Waaij et al. 1995): stands of $S$. procumbens trap vegetative tillers of Spartina anglica and Puccinellia maritima, a process that even continues when stands are deceased. The establishment of common salt marsh grass ( $P$. maritima) is key for moving towards a diversified community (Langlois et al. 2003).

Establishment of Salicornia spp. is influenced by multiple environmental variables, and synergistic (or antagonistic) effects between environmental variables may occur (Keiffer et al. 1994; Ungar 1978; Xie et al. 2019). An inundationfree period of at least 2 days is essential to initiate germination (Wiehe 1935). Air temperature is a key factor, and low temperatures prevent seeds from germinating in winter (Khan et al. 2000), whereas higher temperatures stimulate germination (Ungar 1967). Rainfall increases germination success and seedling survival, by both increasing soil moisture and reducing soil salinity (Noe and Zedler 2001; Xie et al. 2019). Successful establishment can also be impeded by centimetrescale bed-level variation in several ways: (1) winter storms erode the surface layer including newly dispersed seeds, reducing seed availability in spring (van Regteren et al. 2019), (2) high sedimentation and erosion rates in the initial life stages lead to increased perennial seedling mortality (Bouma et al. 2016; Cao et al. 2018), and (3) erosion of the soil will wash away seedlings due to insufficient root anchorage (Houwing 2000; Smit van der Waaij et al. 1995). Thus, multiple environmental variables are expected to affect the successful completion of the Salicornia spp. life cycle in the transition zone but so far, field-based studies including a large array of environmental conditions are still lacking.

This field study aimed to disentangle the multiple environmental factors that control (i) initiation of germination (i.e. presence or absence of germination), (ii) germination success (i.e. germinated seeds that survive into seedlings) and (iii) mortality (i.e. loss of seedlings) before seed-set of $S$. procumbens. In the transition zone, seeds were supplied in $1 \mathrm{~m}^{2}$ plots at the salt marsh edge and further seawards on the intertidal flat. Germination and mortality were monitored throughout the growing season. We hypothesise that (1) increased temperature and precipitation will have a positive effect on the initiation of germination; (2) germination success for both natural and supplied seeds of $S$. procumbens will be higher at the vegetation edge than on the intertidal flat; and (3) a dynamic bed level will increase seedling mortality.

\section{Methods}

\section{Study Area}

We used a naturally developing salt marsh in the Wadden Sea, Westhoek, The Netherlands, as our model system (Fig. 1). The past two decades, the marsh has been expanding step-wise laterally onto the tidal flats as well as along the dike (Baptist et al. 2019b). Stable periods alternated with periods of expansion, while the marsh steadily accreted vertically (Baptist et al. 2019a). The experiment was executed in the south west area of the Westhoek marsh, where vegetation has developed in a narrow stretch along the dike but has not expanded seawards since 2015 (Baptist et al. 2019b). This established marsh contains species typical for high, low and pioneer marshes (Petersen et al. 2014). Close to the marsh edge, the vegetation community is dominated by seed reproducing species such as S. procumbens, Suaeda maritima, Atriplex portulacoides and Aster tripolium. The pioneer zone is dominated by the annual $S$. procumbens and patches of the perennial S. anglica (common cordgrass). Seawards of the salt marsh, a transition zone is present with $S$. procumbens individuals occurring sparsely.

The mud content (sediment grain size below $63 \mu \mathrm{m}$ ) of the sediment was around $68 \%$, and sediment grain size distribution is similar across the salt marsh to tidal flat interface. Mean high water in 2017 was 0.95 m NAP (Dutch Ordnance Datum); the tidal amplitude is approximately $3 \mathrm{~m}$ during spring tide and $1.5 \mathrm{~m}$ during neap tide. 


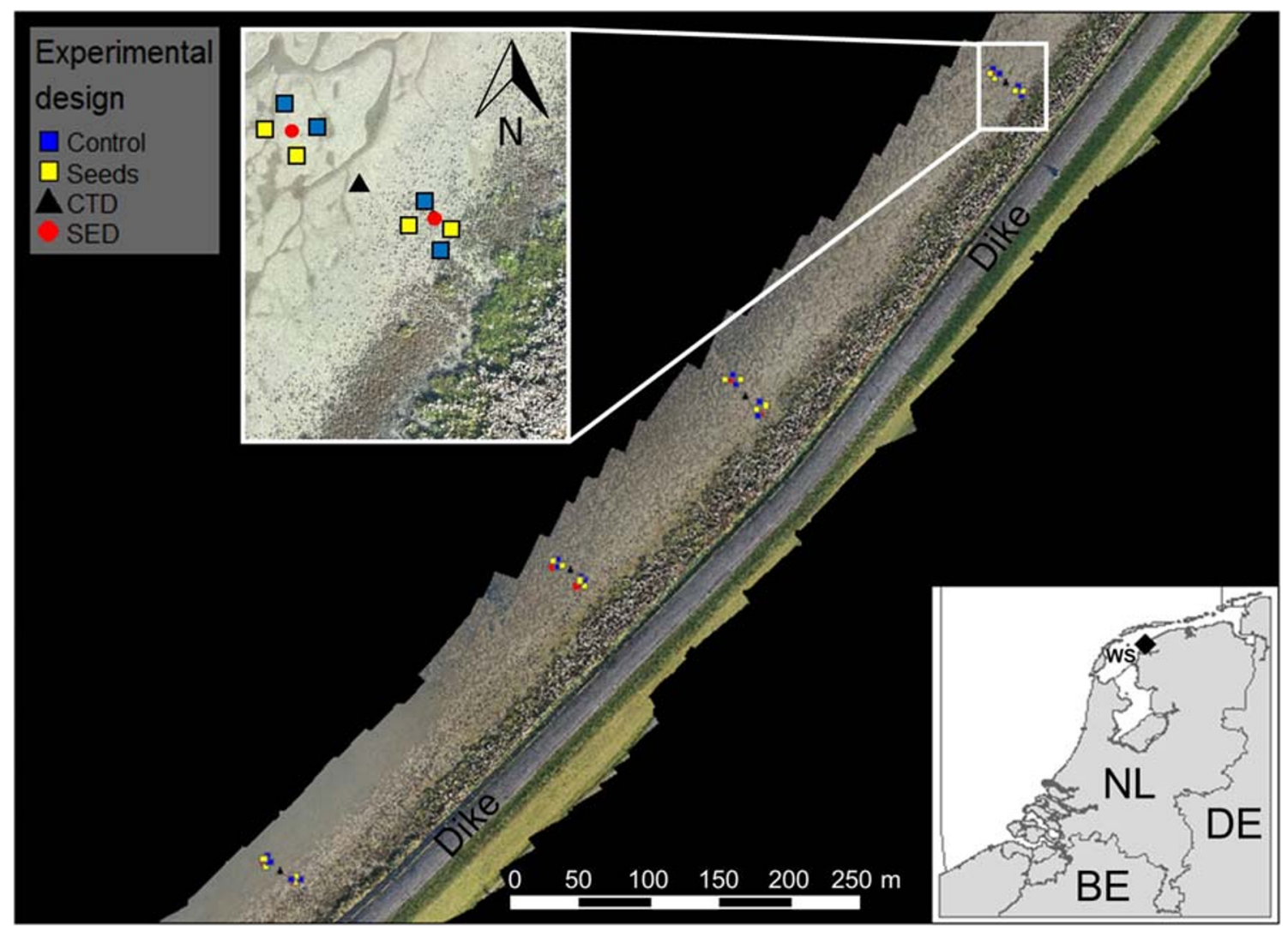

Fig. 1 Four experimental locations placed perpendicular to the coastline. Upper inset: Experimental design of one location, containing 2 blocks with four plots. Two plots with seeds (yellow squares) and two plots without as a control (blue squares) were placed at two positions at the vegetation edge and $10 \mathrm{~m}$ seawards at the intertidal flat; plots were $1 \mathrm{~m}^{2}$. To measure inundation, conductivity temperature depth devices (CTD;

\section{Experimental Design}

A field experiment in the transition zone was performed during the growing season of $S$. procumbens, from April to September 2017 (Davy et al. 2001). The experiment was repeated simultaneously at four locations distributed along a $1.2-\mathrm{km}$ stretch of salt marsh parallel to the dike (Fig. 1). Each location contained two experimental blocks, with four plots in a randomized block design each. Blocks were located in the transition zone, one block at the vegetation edge and one block $10 \mathrm{~m}$ seaward on the bare intertidal flat (Fig. 1). Each block contained two replicates of two treatments: seed-addition and control, amounting to a total of 16 seed-addition plots and 16 control plots. Surface elevation of each plot was measured with a real-time kinematic DGPS at the start of the experiment. Difference in elevation between the vegetation edge and bare intertidal flat plots was on average $5.5 \pm 0.5 \mathrm{~cm}$.

\section{Experimental Seed Addition}

S. procumbens vegetation was collected at the vegetation edge of the same marsh in fall 2016, dried and stored in the dark black triangles) were placed in the middle of the two blocks. To measure bed-level height, two surface elevation dynamic devices (SED; red circles) were placed in each block. Lower inset: The study area Westhoek (black diamond) is located in the Dutch (NL) part of the Wadden Sea (WS)

until use. Dry plants were abraded to remove the seeds from the adult plants. An abundant amount of seeds was divided into 18 portions, and each seed batch was mixed with $500 \mathrm{~mL}$ of locally obtained sediment. Two portions were evenly spread out in a climate chamber, and germination was followed for 5 weeks to determine viability of the $S$. procumbens seeds, which were approximately 400 viable seeds per portion. The remaining 16 seed mixtures were spread on the soil surface in a thin layer, to avoid immediate wind dispersal. Seeds were added to the experimental plots in the field in the third week of April 2017, the other 16 experimental plots served as controls (Fig. 1).

\section{Assessment of Germination Occurrence, Germination Success and Seedling Mortality}

Germination and mortality before seed-set (hereafter referred to as mortality) of $S$. procumbens were assessed 11 times from April until September 2017 in each plot. Each $1 \mathrm{~m}^{2}$ plot was subdivided into 16 subplots of $0.25 \times 0.25 \mathrm{~m}$ in size. Subplots allowed discrimination between germination and mortality within plots. The number of individuals in each subplot was 
recorded at each visit. The subplot data were then used to determine the number of newly germinated individuals as well as the number that had died during each interval, within each plot. For example, at time $x$ in plot $y$, one seedling was recorded in each of three subplots: B, E and N (amounting to three individuals in total). On the next visit, time $x+1$ at this plot, two seedlings in subplot $\mathrm{B}$ and one in $\mathrm{E}, \mathrm{L}$ and $\mathrm{P}$ were counted (amounting to 5 individuals in total). In that interval, the number of germinated individuals in plot $y$ was 3 , because subplots $\mathrm{B}, \mathrm{L}$ and $\mathrm{P}$ have each acquired one new seedling. Mortality of plot $y$ was 1 , because the individual in subplot $\mathrm{N}$ had died, the probability of dying was thus $33 \%$.

\section{Sediment Dynamics, Hydrological and Meteorological Conditions}

To measure high-resolution, temporal bed-level variations, a Surface Elevation Dynamics (SED) instrument (Hu et al. 2015) was placed in the centre of each block (Fig. 1). The SED sensors contain 200 adjacent light-sensitive cells of $2 \mathrm{~mm}$ in height covering $400 \mathrm{~mm}$ in total. Upon installation, half of the cells $(200 \mathrm{~mm})$ emerged above the soil surface, the other half was inserted in the soil to ensure accurate measurements of both sedimentation and erosion. The SEDs measured the bed level every $30 \mathrm{~min}$, when emerged and during daylight hours. They were anchored firmly in the soil with a metal rod of $1.2 \mathrm{~m}$. The data were retrieved from the logger once during the experiment (while the instrument remained in the sediment for continuity in the measurements) and at the end of the experiment. The SED data were converted into bed-level change information following Willemsen et al. (2018). SED time series were subdivided into the same intervals as those in which the vegetation was assessed. For each plot and each interval, values for bed-level difference, sedimentation and erosion were derived relative to the initial bed level (average of first five bed-level measurements) in that interval. The average of the five highest consecutive measured bed-level values was subtracted from the initial bed level, to obtain a sedimentation value (similar for lowest and final bed-level values, respectively for erosion and bed-level difference). This was repeated for all 11 intervals and plots.

Additionally, four Conductivity Temperature Depth instruments (CTD-diver, Eijkelkamp Soil \& Water) were placed, one in each middle of two blocks (Fig. 1). The CTDs measured at an interval of $3 \mathrm{~min}$ to monitor accurate on-site water levels and temperature. CTD time series were subdivided into the same intervals and processed to gather data on temperature, longest inundation-free period (days), inundation frequency (times day ${ }^{-1}$ ) and inundation duration (hours day ${ }^{-1}$ ) for each block and interval. Meteorological data from weather station Leeuwarden (http://www.knmi.nl/kennis-endatacentrum) at $15 \mathrm{~km}$ distance was used to correct for air pressure variation in CTD data and to obtain precipitation data.

\section{Statistical Analyses}

The environmental variables were tested for their effect on the initiation of germination, germination success and mortality of S. procumbens. Variables included average temperature, precipitation, inundation-free period, inundation frequency, inundation duration, sedimentation, erosion, bed-level difference and initial elevation. Inundation duration was not simultaneously used with inundation frequency due to collinearity between these covariates. This was also the case for sedimentation and bed-level difference. Additional explanatory variables in the models included plot ID, a random effect to correct for the correlation between measurements within the same plot (Pinheiro and Bates 2000); location, to identify potential nesting effects; and position (vegetation edge or intertidal flat) to check for possible effects of distance to a seed source. However, neither position nor location was significant in the final model results, and therefore, these variables were removed to simplify the models. Temporal correlation between residuals was assessed, but residuals did not show patterns through time. Because of the large number of variables, we used forward selection to determine which variables significantly affected germination and mortality. Akaike Information Criterion (AIC) scores were used to select the best model (Brooks et al. 2017), and likelihood ratio tests (LR) to determine the significance of individual parameters in each model.

Solely seed-addition plots were selected for analysis of germination occurrence and success because few $S$. procumbens individuals germinated in the control plots. Thus, seed limitation was no longer a possible cause for the observed differences in germination. Exploratory analyses gave no indication for non-linearity and germination was therefore analysed using a generalized linear mixed model using template model builder (glmmTMB) (Brooks et al. 2017). The germination analysis was split in two parts; first, occurrence of germination was analysed using a binomial model. The final equation for the final model reads as:

$G=$ temp + sed + plotID $+\varepsilon$

where $G$ stands for germination (absence/presence), temp is temperature $\left({ }^{\circ} \mathrm{C}\right)$, sed is the sedimentation rate $\left(\mathrm{mm} \mathrm{day}^{-1}\right)$, plotID is the random effect and $\varepsilon$ is the error.

Secondly, once germination was initiated, we analysed which environmental variables influenced germination success (number of plants germinated). Models included an offset (offset $=\log ($ days $)$ ) together with a log-link and a negative binomial family for the error distribution to adjust for the difference in germination periods (more time between two visits can lead to an increase in germination success). A 
negative binomial error distribution was chosen because the Poisson data was overdispersed. The negative binomial model is well equipped to cope with the relatively large number of zeros $(48 \%)$. The final equation for this model reads as:

$G n=$ offset + sed + precip + inunfree + plotID $+\varepsilon$

where $\mathrm{Gn}$ stands for germination success (number of individuals), offset is the offset, sed is the sedimentation rate $\left(\mathrm{mm}\right.$ day $\left.^{-1}\right)$, precip is precipitation rate for each period $\left(\mathrm{mm} \mathrm{day}{ }^{-1}\right)$, inunfree is the maximum inundation-free period (days), plotID is the random effect and $\varepsilon$ is the error.

Mortality was analysed only in plots with $S$. procumbens seedlings present, including seed-addition and control plots. Exploratory analyses gave no indication for non-linearity, and mortality was therefore analysed using a generalized linear mixed model (glmmTMB). A weights factor was added to incorporate the total number of individuals for each plot. A zero-inflated binomial model was used to ensure that the model could cope with the large number of zeros. The final zeroinflated binomial model was:

$M=$ inunfree + freq + bldif + plotID $+\varepsilon$

where $M$ stands for probability of mortality, inunfree is the maximum inundation-free period (days), freq is inundation frequency (average times day ${ }^{-1}$ ), bldif is the bed-level difference $(\mathrm{mm})$, plotID is the random effect and $\varepsilon$ is the error.

All model predictions were executed with the mean random effect (i.e. mean $=0$ ), and if more than two variables were modelled the mean of the remaining, least influential variable was used. Model predictions were displayed with $95 \%$ confidence intervals. All statistical analyses were performed with the statistical program R (R Core Team 2018) using additional packages 'plyr' (Wickham 2011), 'ggplot2' (Wickham 2009), 'Ime4' (Bates et al. 2015) and 'glmmTMB' (Magnusson et al. 2017). The protocols by Zuur et al. (2010) and Zuur and Ieno (2016) were used for data exploration and assessing the assumptions of subsequent analyses.

\section{Results}

Natural seed germination was low with 20 germinated seedlings in the control plots as opposed to 260 individuals in the seed-addition plots (Fig. 2). The seed-addition plots thus contained 12.5 times more individuals than natural control plots. Of the 20 seedlings in the control treatment, 16 germinated at the vegetation edge and 4 on the intertidal flat. From the naturally present seedlings, one individual survived until the end of the experiment. Supplying seeds led to an increase of $S$. procumbens individuals in the transition zone, at both the vegetation edge and the intertidal flat (Fig. 2). Germination of S. procumbens started halfway May and continued until the end of August. Mortality occurred from the moment seedlings were present but was highest in August and September (Fig. 2). Of the 260 seedlings established in the seedaddition plots, 26 individuals reached the seed-set stage. The variability of the environmental factors used for the analyses of germination occurrence, success and mortality during the experimental period is displayed in Fig. 3. The temperature data obtained from the four CTDs was similar at all blocks, thus depicted only once (Fig. 3).

\section{Germination Occurrence and Germination Success}

Temperature and sedimentation significantly influenced the absence and presence of germination (Table 1). Once germination was initiated, average temperature had increased by $6{ }^{\circ} \mathrm{C}$, from 10.5 to $16.5^{\circ} \mathrm{C}$ (Fig. 3). Temperature had a positive effect, and sedimentation had a negative effect (Table 1). Sedimentation rates varied between 0 and $4.8 \mathrm{~mm} \mathrm{day}^{-1}$, and total sedimentation ranged from 0 to $110 \mathrm{~mm}$. Sedimentation, precipitation and an inundation-free period were significant factors in determining germination success (Table 1). The model results and environmental field data were used to visualize the combined effects of precipitation and sedimentation on germination success in Fig. 4. Comparing germination success across a sedimentation gradient and for three precipitation levels showed that the highest number of germinated individuals was found at low sedimentation and high precipitation rates (Fig. 4). Low $\left(1 \mathrm{~mm} \mathrm{day}^{-1}\right)$, mean $\left(3.4 \mathrm{~mm}\right.$ day $\left.^{-1}\right)$ and high $\left(7 \mathrm{~mm}\right.$ day $\left.^{-1}\right)$ precipitation levels per interval were based on local KNMI (The Royal Netherlands Meteorological Institute) data during the experiment. Germination success was cut in half when sedimentation rates of $0.5 \mathrm{~mm} \mathrm{day}{ }^{-1}$ were reached and nearly diminished above $2 \mathrm{~mm}$ day $^{-1}$ (Fig. 4). When seeds were supplied, initiation of germination as well as germination success was similar between the vegetation edge and the intertidal flat. Neither initiation nor success was significantly affected by initial elevation (Table 1 ). Experimental plots were nested together in blocks (Fig. 1), which did not affect germination occurrence or success (Table 1).

\section{Seedling Mortality}

Mortality of $S$. procumbens increased with a longer inundation-free period (i.e. drought stress), with increased inundation frequency (hydrodynamic stress), and with increasing bed-level difference (dislodgement) (Table 1). The environmental field data and model results were used to visualize the combined effects of inundation-free period and inundation frequency on seedling mortality in Fig. 5. Probability of mortality was modelled along an inundation-free gradient, ranging from 1.7 to 7 days (Fig. 3), including three levels of inundation frequency (Fig. 5). High, mean and low frequencies were based on measured field values, respectively, 1.4, 1.1 and 0.6 inundations per day. Greater bed-level variation slightly 
Fig. 2 Germination (positive values) and mortality (negative values) of $S$. procumbens individuals in each plot $\left(1 \mathrm{~m}^{2}\right)$ and period. Both treatments are shown, control on the left and seed-addition on the right. The colour of the triangle indicates the position, green for vegetation edge and orange for the intertidal flat, no differences were found between edge and flat. Points are slightly offset along the $x$-axis to reduce overlap. The light grey area is the period without germination; the grey area is a period with predominantly germination and some mortality; the darker grey area is the period with predominantly mortality and some germination

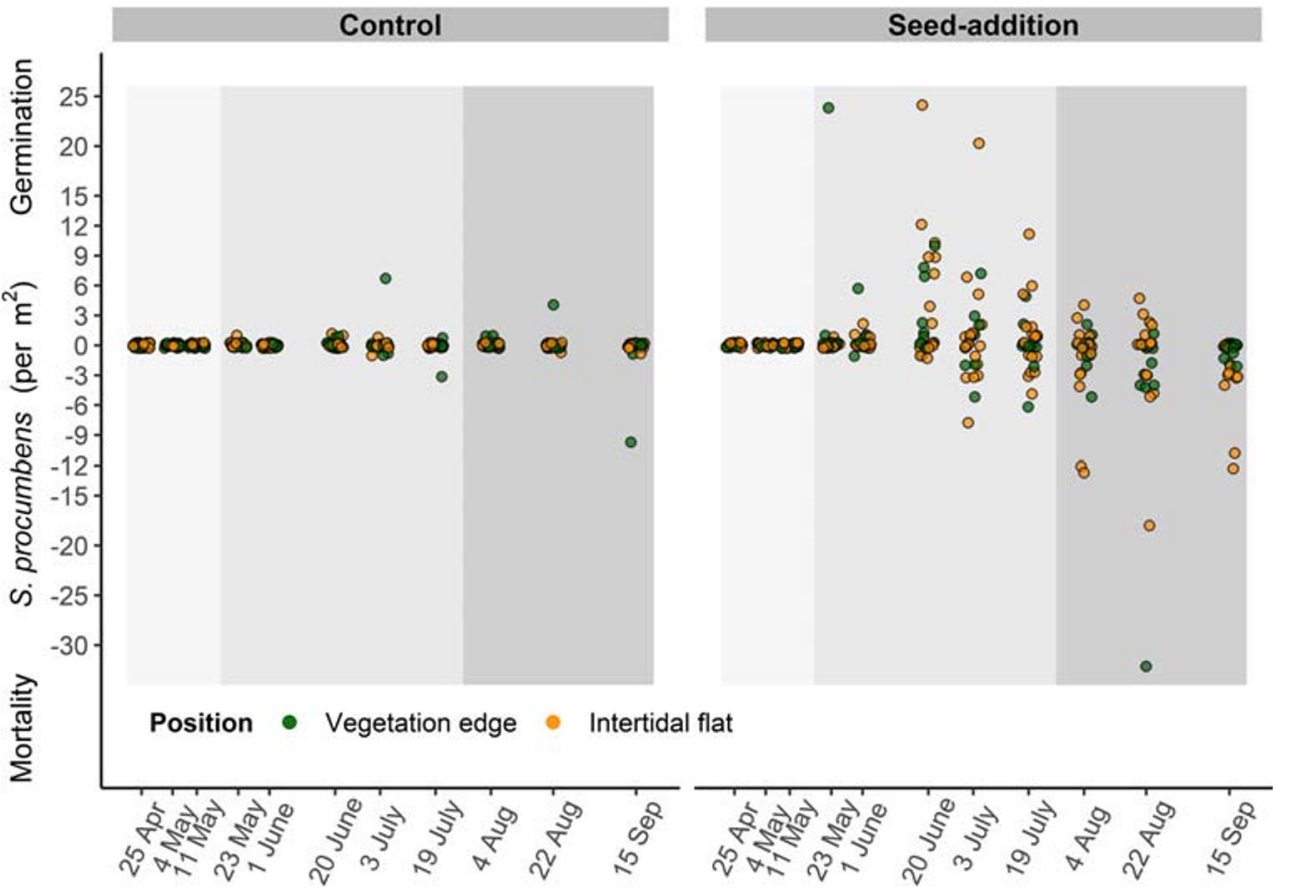

increased mortality (Table 1). The measured bed-level difference within one period ranged up to $45 \mathrm{~mm}$ (Fig. 3). Mortality was similar between the vegetation edge and the intertidal flat (Table 1).

\section{Discussion}

The aim of this study was to identify the environmental variables that determine the establishment success of the annual $S$. procumbens in the transition zone located between salt marsh and intertidal flat (Figs. 2 and 3). The experiment confirmed our first hypothesis that temperature is influential for germination to occur. Germination was not initiated when temperature was below $10.5^{\circ} \mathrm{C}$. The impact of precipitation was not significant on the initiation of germination, but did increase germination success (Fig. 4). In contrast to our second hypothesis, we did not find any significant effect from location (vegetation edge vs. intertidal flat) on germination or mortality. In line with our third hypothesis, we found that sedimentation had a strong negative effect on germination (initiation and success), while bed-level variation increased seedling mortality. Additionally, we found that both frequent inundation and extended inundation-free periods increased seedling mortality (Fig. 5 and Table 1).

\section{Difference between Seed-Addition and Control Treatment}

Natural establishment of $S$. procumbens in the control treatment was very low. This may indicate that seed availability is limiting natural colonization of S. procumbens in the transition zone, as was already shown for a similar marsh area nearby (van Regteren et al. 2019). It is often assumed that seeds are not limited when a seed source is close by (Erfanzadeh et al. 2010b; Friess et al. 2012; Rand 2000; Wolters et al. 2005; Zhu et al. 2014). S. procumbens seeds do not have extensive floating capacity and disperse at a close range (Huiskes et al. 1985; Rand 2000). A local seed source was present, attested by dead standing material from the previous year (Ellison 1987; Rand 2000). In the field, however, only 20 individuals germinated naturally, as opposed to 260 when seeds were added (Fig. 2). It is probable that natural seed availability is not sufficient for increased establishment of $S$. procumbens in the transition zone (van Regteren et al. 2019). Causes for seed limitation in the control plots could be low viability of seeds (Erfanzadeh et al. 2010a), erosion after seed dispersal (van Regteren et al. 2019) or burial through sedimentation or bioturbation (van Regteren et al. 2017; Zhu et al. 2014). More individuals established from natural germination at the vegetation edge, $80 \%$, than further seawards on the tidal flat, $20 \%$. Although it could not be tested statistically due to low germination rates, this could indicate that natural seed availability was higher at the vegetation edge. Potentially because the edge plots were closer to a seed source or the marsh edge may provide shelter during storms. When seeds were supplied, similar germination and mortality patterns between the vegetation edge and intertidal flat occurred. These may be explained by the lack of variation in elevation. Pioneer vegetation can establish at an elevation of $0.5 \mathrm{~m}$ below mean high water (Wang and Temmerman 2013). At this study site, mean high water was $0.95 \mathrm{~m}$ and elevation in the transition zone 
Fig. 3 Visual representation of environmental variables measured throughout the experiment and used in the analyses. Precipitation and temperature, minimum (blue), mean (black) and maximum (red) were determined on a marsh scale (top 2 graphs). Sediment and inundation characteristics are displayed per block (location/position combination); locations are indicated using shapes and position using colour (green at the marsh edge and orange for the intertidal flat). The light grey area is the period without germination; the grey area is a period with predominantly germination and some mortality; the darker grey area is the period with predominantly mortality and some germination
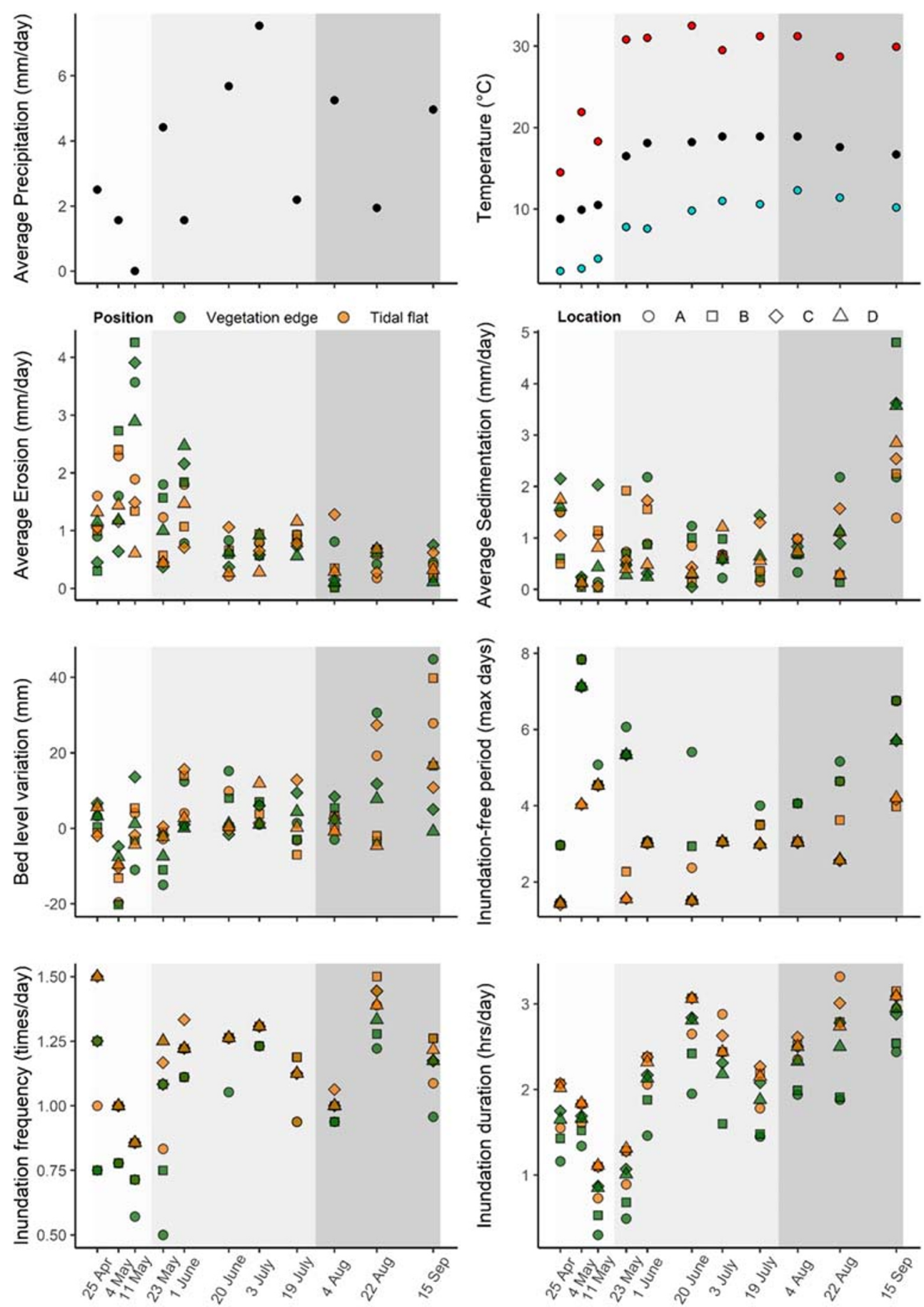

ranged between 0.88 and $1.04 \mathrm{~m}$, fulfilling the elevation requirement at all experimental plots. Germination initiation, success and mortality were unaffected by the initial elevation (Table 1).

\section{Temperature and Precipitation Promote Germination}

Temperature largely determined whether seed germination was initiated (Table 1). Average temperature was lower than usual for the period end of April to half of May. Germination only occurred after the average temperature had risen above $10.5{ }^{\circ} \mathrm{C}$ (Figs. 2 and 3). This is in agreement with previous studies showing that low temperatures inhibit germination, by forcing seeds to remain dormant (Khan et al. 2000) and increased temperature enhances germination (Huiskes et al. 1985; Ungar 1967). Exact temperature thresholds for germination were not determined in this study and should be investigated in a laboratory environment. Synergistic effects between environmental variables that improve the germination 
Table 1 Model variables and results with respect to (i) initiation of germination (i.e. absence or presence), (ii) germination success (i.e. seeds that establish) and (iii) mortality (seedlings that die before seed-set). LR are likelihood ratio tests to estimate the significance of each variable included in the final model. Est stands for the estimates \pm SE. N.S. stands for not significant, meaning that the final model did not contain those variables based on forward model selection using AIC. The random effect was always added; the zero-inflation model component was only required in the mortality analysis

Fig. 4 Model based predicted germination success (number of germinated individuals per $\mathrm{m}^{2}$ ) depending on sedimentation rates at three different precipitation rates: high, mean and low, respectively depicting $7.5,3.4$ and $1 \mathrm{~mm}$ precipitation day ${ }^{-1}$. The shaded grey areas correspond to the $95 \%$ confidence interval for the predictions

\begin{tabular}{|c|c|c|c|c|}
\hline Environmental variables & Units & $\begin{array}{l}\text { Germination } \\
\text { initiation }\end{array}$ & $\begin{array}{l}\text { Germination } \\
\text { success }\end{array}$ & Mortality \\
\hline Inundation frequency (times day ${ }^{-1}$ ), Fig. 5 & $\begin{array}{l}\mathrm{LR}_{\mathrm{df}=1} \\
\mathrm{p} \\
\text { Est. }\end{array}$ & N.S. & N.S. & $\begin{array}{l}18.5 \\
<0.0001 \\
2.73 \pm 0.64\end{array}$ \\
\hline Inundation duration $\left(\mathrm{h} \mathrm{day}^{-1}\right)$ & $\mathrm{LR}_{\mathrm{df}=1}$ & N.S. & N.S. & N.S. \\
\hline Inundation-free period (days), Fig. 5 & $\begin{array}{l}\mathrm{LR}_{\mathrm{df}=1} \\
\mathrm{p} \\
\text { Est. }\end{array}$ & N.S. & $\begin{array}{l}4.3 \\
0.039 \\
-0.31 \pm 0.15\end{array}$ & $\begin{array}{l}51.2 \\
<0.00001 \\
0.84 \pm 0.12\end{array}$ \\
\hline Average temperature $\left({ }^{\circ} \mathrm{C}\right)$, Fig. 3 & $\begin{array}{l}\mathrm{LR}_{\mathrm{df}=1} \\
\mathrm{p} \\
\text { Est. }\end{array}$ & $\begin{array}{l}63.1 \\
<0.00001 \\
0.63 \pm 0.15\end{array}$ & N.S. & N.S. \\
\hline Precipitation $\left(\mathrm{mm}\right.$ day $\left.^{-1}\right)$, Fig. 4 & $\begin{array}{l}\mathrm{LR}_{\mathrm{df}=1} \\
\mathrm{p} \\
\text { Est. }\end{array}$ & N.S. & $\begin{array}{l}4.9 \\
0.026 \\
0.016 \pm 0.07\end{array}$ & N.S. \\
\hline Sedimentation ( $\mathrm{mm}$ day ${ }^{-1}$ ), Fig. 4 & $\begin{array}{l}\mathrm{LR}_{\mathrm{df}=1} \\
\mathrm{p} \\
\text { Est. }\end{array}$ & $\begin{array}{l}12.4 \\
0.0004 \\
-1.12 \pm 0.38\end{array}$ & $\begin{array}{l}22.1 \\
<0.00001 \\
-1.35 \pm 0.32\end{array}$ & N.S. \\
\hline Erosion $\left(\mathrm{mm} \mathrm{day}^{-1}\right)$ & $\mathrm{LR}_{\mathrm{df}=1}$ & N.S. & N.S. & N.S. \\
\hline Bed-level difference (mm), Fig. 3 & $\begin{array}{l}\mathrm{LR}_{\mathrm{df}=1} \\
\mathrm{p} \\
\text { Est. }\end{array}$ & N.S. & N.S. & $\begin{array}{l}5.7 \\
0.017 \\
0.024 \pm 0.01\end{array}$ \\
\hline Initial elevation (m NAP) & $\mathrm{LR}_{\mathrm{df}=1}$ & N.S. & N.S. & N.S. \\
\hline Plot ID (random effect) & $\begin{array}{l}\mathrm{LR}_{\mathrm{df}}=1 \\
\mathrm{p}\end{array}$ & N.S. & $\begin{array}{l}5.1 \\
0.023\end{array}$ & $\begin{array}{l}22.88 \\
<0.0001\end{array}$ \\
\hline Location (nesting factor) & $\mathrm{LR}_{\mathrm{df}=1}$ & N.S. & N.S. & N.S. \\
\hline Position (edge vs. flat) & $\mathrm{LR}_{\mathrm{df}=1}$ & N.S. & N.S. & N.S. \\
\hline Zero-inflation & $\begin{array}{l}\mathrm{LR}_{\mathrm{df}=1} \\
\mathrm{p} \\
\text { Est. }\end{array}$ & NA & NA & $\begin{array}{l}81.4 \\
<0.00001 \\
-1.11 \pm 0.30\end{array}$ \\
\hline$n$ & & 176 & 112 & 132 \\
\hline
\end{tabular}




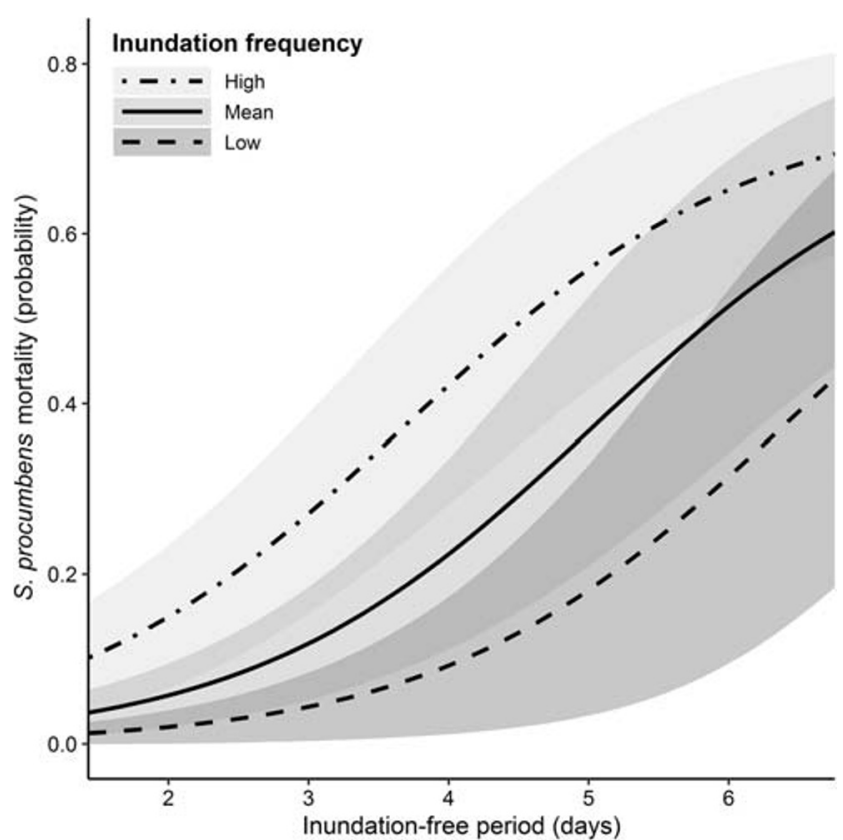

Fig. 5 Model based predicted seedling mortality (probability) before seed-set as a function of an increasing inundation-free period (i.e. potential drought build up) for three different inundation frequencies: high, mean and low, respectively, depicting 1.4, 1 and 0.6 inundations day ${ }^{-1}$. The shaded grey areas correspond to the $95 \%$ confidence interval for the predictions

rates may occur, for example between higher temperature and lower salinity (Huiskes et al. 1985; Ungar 1967). When temperatures increase early in the season, the growing season can be prolonged and early cohorts have advantage over later cohorts (Ungar 1987). The length of the growing season will affect the size of $S$. procumbens individuals and its reproductive success (Davy et al. 2001). Larger plants carry more seeds and thus have a higher reproductive output (Boorman et al. 2001), which may improve the potential for (natural) marsh expansion.

Precipitation had no significant effect on the initiation of germination but had a strong positive effect on the germination success of $S$. procumbens (Fig. 4 and Table 1). This neutral effect on the initiation is probably because rainfall occurred frequently throughout the study period. There was only one interval that contained no precipitation, which was in early May before germination had initiated (Figs. 2 and 3) (Noe and Zedler 2001; Xie et al. 2019). From Salicornia europaea, Salicornia bigelovii and Salicornia virginica, it is known that fresh water input (i.e. precipitation) stimulates seedling germination and establishment (Carter and Ungar 2003; Noe and Zedler 2001; Zedler et al. 2003). Rainfall can affect soil conditions dually, decreasing soil salinity while increasing soil moisture (Noe and Zedler 2001; Xie et al. 2019), which both can increase germination success. In dry years and/or in areas where precipitation has reduced or shifted, the impact of precipitation is expected to be larger (Noe and Zedler 2001; Strain et al. 2017; Xie et al. 2019).
We expect that synergistic (antagonistic) effects are likely to occur when precipitation and increased temperature coincide (deviate).

\section{Inundation Regime Increases Seedling Mortality}

Germination occurrence and success were not directly influenced by inundation frequency (ranging from 0.5 to 1.5 times per day). The inundation-free period had a small effect on germination success (Table 1). Inundation frequency has been suggested as the main factor that regulates the seaward extent of salt marsh vegetation establishment (Balke et al. 2016), possibly by affecting seedling mortality. The inundation-free period does indeed provide an essential hydrodynamically undisturbed window for germination (Wiehe 1935). In our study, the observed inundation-free period during the experiment ranged from 1.7 to 7 days (Fig. 3) which complies with the minimum requirement of 2 days free of disturbance (Wiehe 1935).

Mortality of S. procumbens was influenced by increasing inundation frequency as well as with increasing length of inundation-free periods (Fig. 5 and Table 1). High hydrodynamic stress, due to frequent inundation, enhances the risk of seedlings getting washed away by strong waves and currents (Houwing 2000). An extended inundation-free period excludes hydrodynamic stress but does contribute to soil dehydration and increased soil salinity. This may be (partially) countered by frequent precipitation. Soil desiccation may lead to desiccation cracks and thus less strongly rooted vegetation (Noe and Zedler 2001) and severe drought could even change the species composition in a salt marsh (Strain et al. 2017). Seedling mortality in our study was highest when an inundation-free period was followed by frequent inundation and high bed-level variation (Figs. 2 and 3, 22 Aug). We hypothesise that the formation of desiccation cracks dislodged the roots of the plants in our study site and they got washed away during strong currents and waves that followed. It is probable that the order of events affects the synergistic effect on the dislodgement of seedlings. The disappearance of Salicornia spp. can be regarded as an early warning signal for changing inundation regimes (Balke et al. 2016).

\section{Sedimentation Reduced Establishment}

Sedimentation appeared to hamper the initiation of germination and high sedimentation rates also reduced germination success (Figs. 3 and 4). For S. europaea and S. procumbens, the maximum depth from which germinated seeds were able to reach the surface was found to be $10 \mathrm{~mm}$ (Huiskes et al. 1985). As total sedimentation ranged from 0 to $110 \mathrm{~mm}$, this becomes precarious when sediment deposition occurs in sudden events. We observed such sudden events, of up to multiple centimetres in 1 tide, in our $30 \mathrm{~min}$ SED data. Freshly sprouted 
S. procumbens are only a few millimetres tall and will be buried completely when sudden sedimentation events occur. Quantifying exact sedimentation thresholds for S. procumbens can be achieved using burial experiments, as exemplified for S. anglica, and will depend on seedling age (Cao et al. 2018; Poppema et al. 2019). Sedimentation had no direct significant effect on the mortality, but the bed-level variation did significantly increase mortality (Table 1). Research on seedling responses related to sediment dynamics is scarce and limited to the lab. Larger seedlings are better at outgrowing deposited sediment as shown for Spartina anglica (Cao et al. 2018). $S$. europaea can cope with low sedimentation rates as well (Boorman et al. 2001), but the rates used in their experiment $\left(0.16 \mathrm{~mm} \mathrm{day}^{-1}\right)$ were much lower compared to our field values (average $1.01 \mathrm{~mm} \mathrm{day}^{-1}$ ). The establishment success of marsh vegetation will be undermined when individuals cannot outgrow sedimentation rates. Other species, for example the perennial P. maritima, thrive on sediment deposition. They form accretion hummocks which promote a stable and diversified marsh community (Langlois et al. 2003). Vegetation establishment is facilitated by a stable soil (Bouma et al. 2016), thus a dynamic bed level is expected to set additional pioneer vegetation establishment and survival boundaries.

Neither S. procumbens germination nor mortality was significantly affected by erosion (Table 1), while pioneer species S. anglica was more negatively affected by erosion than by sedimentation (Cao et al. 2018). However, erosion rates were highest at the start of the experiment, when germination did not yet occur (Figs. 2 and 3), which can explain the lack of effect from erosion found in this study. It is expected that increased erosion rates, occurring when seedlings have just germinated, would have shown a different response. Young established seedlings were observed to have deep roots in the transition zone and the root system may be adaptive regarding the stressful conditions at the marsh edge. A similar response in root investment was shown for S. anglica seedlings regarding wave stress (Cao et al. 2019).

The transition zone is the vital area for salt marsh expansion but it is also where bed level is very dynamic (Widdows et al. 2008; Willemsen et al. 2018). There is an intricate interplay between the sedimentation and erosion at the salt marsh intertidal flat transition zone. It is essential to distinguish among the geomorphic processes: erosion, sedimentation and bed-level dynamics, to increase the understanding of limitations to vegetation establishment. For the initial establishment phase, annuals and perennials are both vulnerable to high sediment dynamics (Cao et al. 2018, this study). Once established, however, perennials are expected to be less vulnerable than annuals. Surmountable sedimentation, erosion and sediment dynamics are species specific but also life stage specific and depend on temporal and spatial manifestations of sediment dynamics (Bouma et al. 2013; Cao et al. 2018; Langlois et al. 2003; Lo et al. 2017).

\section{Implications for Salt Marsh Expansion}

This marsh consists of a narrow stretch of vegetation along the dike. It has not expanded laterally seawards since 2015, although the bed-level elevation is suitable for vegetation establishment (Baptist et al. 2019b; Wang and Temmerman 2013). A wider marsh would be beneficial to coastal protection and for its value as a nature area (Reise et al. 2010; Temmerman et al. 2013; Willemsen et al. 2020). We found that multiple factors affected the establishment success of $S$. procumbens in our field site. Furthermore, the impact of each factor also depended on the severity of other factors. The density of halophyte seedlings can be quite variable between years (Morzaria-Luna and Zedler 2007). Synergistic effects in weather conditions (for example temperature and precipitation) can greatly influence the start of the growing season, affecting plant sizes and numbers (Ungar 1978). This can have proliferating effects on the next years' reproduction potential (especially for annuals) and hence for salt marsh stability and expansion. Perennial pioneers such as S. anglica may be less affected by years with unfavourable weather conditions due to their ability for rhizomatous and vegetative growth (Zhu et al. 2014), although large expansions of vegetated areas or colonization of new areas are more likely to happen through seed dispersal. Sudden vegetation colonization events are determined by physical windows of opportunity (Balke et al. 2014) and seed availability (van Regteren et al. 2019). This study showed that, additionally, local bed-level dynamics strongly influence the successful completion of the $S$. procumbens lifecycle.

Salt marsh management that aims to restore or stimulate marsh growth through the establishment of pioneer species in the transition zone needs to identify sites which provide appropriate boundary conditions. In addition to the well-known effects of inundation regime and elevation, our study showed that sediment dynamics and seed availability should be included when assessing the potential of areas for salt marsh restoration. Conditions in this study area may apply to other silty areas and areas where the marshes and tidal flats have a dynamic bed level. Locations that do not show marsh expansion despite having a suitable elevation may benefit from high-resolution bed-level measurements and research into the soil seed bank. Even a narrow stretch of marsh vegetation can function as a coastal protection buffer through wave attenuation (Yang et al. 2012). Supplying seeds led to increased establishment of $S$. procumbens. It is expected that the vegetation at the edge provides seeds for continued marsh vegetation establishment. Although the effect of seed supply will differ per area and species used (Lindig-Cisneros and Zedler 2002; Morzaria-Luna and Zedler 2007; Rand 2000), especially marsh restoration sites may benefit from adding seeds to expedite marsh development, provided that they contain the appropriate physical boundary conditions (Lindig-Cisneros 
and Zedler 2002). Wind conditions exert a strong influence on sediment transport in the Wadden Sea (Schulz and Gerkema 2018). Dynamics in intertidal areas may inhibit effective pioneer establishment by reducing germination or increasing mortality before seed-set (Cao et al. 2018; Cao et al. 2019). Furthermore, the role of natural variability in external forcing for the long-term dynamics of biogeomorphic systems deserves emphasis (Balke et al. 2014). Short-term variability in environmental conditions can exert considerable impact on vegetation establishment, especially for annuals such as $S$. procumbens. An additional challenge in salt marsh management is that vegetation establishment opportunities are likely to be influenced by climate change, through increased disturbances by wind and waves (Donat et al. 2011), changes in the precipitation regime (Alley 2004) and altered sediment dynamics (Cahoon and Reed 1995).

Acknowledgements This work is part of the research program 'Sediment for salt marshes: physical and ecological aspects of a Mud Motor' with project number 13888 , which is largely financed by the Netherlands Organization for Scientific Research (NWO). This research received cofunding from EcoShape: Building with Nature and Waddenfonds. Access to the field site is granted by It Fryske Gea. We thank students and volunteers for their assistance in the field. Additionally, we are grateful for the help of C. Sonneveld, M.E.B. van Puijenbroek (WMR), L. van IJzerloo (NIOZ), and P. Willemsen (University of Twente) for processing the raw SED data; I. Colosimo (TU Delft) for the use of the CTD instruments; and S. Kühn and T. Daniels for valuable comments on this manuscript.

Open Access This article is licensed under a Creative Commons Attribution 4.0 International License, which permits use, sharing, adaptation, distribution and reproduction in any medium or format, as long as you give appropriate credit to the original author(s) and the source, provide a link to the Creative Commons licence, and indicate if changes were made. The images or other third party material in this article are included in the article's Creative Commons licence, unless indicated otherwise in a credit line to the material. If material is not included in the article's Creative Commons licence and your intended use is not permitted by statutory regulation or exceeds the permitted use, you will need to obtain permission directly from the copyright holder. To view a copy of this licence, visit http://creativecommons.org/licenses/by/4.0/.

\section{References}

Alley, R.B. 2004. Abrupt climate change. Scientific American 291 (5): 62-69. https://doi.org/10.1038/scientificamerican1104-62.

Balke, T., P.M. Herman, and T.J. Bouma. 2014. Critical transitions in disturbance-driven ecosystems: identifying windows of opportunity for recovery. Journal of Ecology 102: 700-708. https://doi.org/10. 1111/1365-2745.12241.

Balke, T., M. Stock, K. Jensen, T.J. Bouma, and M. Kleyer. 2016. A global analysis of the seaward salt marsh extent: the importance of tidal range. Water Resources Research 52: 1-12. https://doi.org/10. 1002/2015WR018318.

Baptist, M.J., T. Gerkema, B.C. van Prooijen, D.S. van Maren, M. van Regteren, K. Schulz, I. Colosimo, J. Vroom, T. van Kessel, B. Grasmeijer, P. Willemsen, K. Elschot, A.V. de Groot, J. Cleveringa, E.M.M. van Eekelen, F. Schuurman, H.J. de Lange, and M.E.B. van Puijenbroek. 2019a. Beneficial use of dredged sediment to enhance salt marsh development by applying a 'Mud Motor'. Ecological Engineering 127: 312-323. https://doi.org/10. 1016/j.ecoleng.2018.11.019.

Baptist, M.J., J. Vroom, P. Willemsen, M.E.B. Puijenbroek, D.S. Van Maren, P. Van Steijn, and M. Van Regteren. 2019b. Beneficial use of dredged sediment to enhance salt marsh development by applying a 'mud motor': evaluation based on monitoring. https://doi.org/10. $18174 / 500109$

Bates, D., M. Machler, B.M. Bolker, and S.C. Walker. 2015. Fitting linear mixed-effects models using 1me4. Journal of Statistical Software 67: 1-48. https://doi.org/10.18637/jss.v067.i01.

Boorman, L.A., J. Hazelden, and M. Boorman. 2001. The effect of rates of sedimentation and tidal submersion regimes on the growth of salt marsh plants. Continental Shelf Research 21: 2155-2165. https:// doi.org/10.1016/S0278-4343(01)00049-8.

Bouma, T., S. Temmerman, L. van Duren, E. Martini, W. Vandenbruwaene, D. Callaghan, T. Balke, G. Biermans, P. Klaassen, and P. van Steeg. 2013. Organism traits determine the strength of scale-dependent bio-geomorphic feedbacks: a flume study on three intertidal plant species. Geomorphology 180: 5765. https://doi.org/10.1016/j.geomorph.2012.09.005.

Bouma, T.J., J. van Belzen, T. Balke, Z. Zhu, L. Airoldi, A.J. Blight, A.J. Davies, C. Galvan, S.J. Hawkins, and S.P. Hoggart. 2014. Identifying knowledge gaps hampering application of intertidal habitats in coastal protection: opportunities \& steps to take. Coastal Engineering 87: 147157. https://doi.org/10.1016/j.coastaleng.2013.11.014.

Bouma, T., J. van Belzen, T. Balke, J. van Dalen, P. Klaassen, A. Hartog, D. Callaghan, Z. Hu, M. Stive, and S. Temmerman. 2016. Shortterm mudflat dynamics drive long-term cyclic salt marsh dynamics. Limnology and Oceanography 61: 2261-2275. https://doi.org/10. 1002/lno.10374.

Brooks, M.E., K. Kristensen, K.J. van Benthem, A. Magnusson, C.W. Berg, A. Nielsen, H.J. Skaug, M. Machler, and B.M. Bolker. 2017. glmmTMB balances speed and flexibility among packages for zeroinflated generalized linear mixed modeling. The R Journal 9: 378400. https://doi.org/10.32614/RJ-2017-066.

Cahoon, D.R., and D.J. Reed. 1995. Relationships among marsh surfacetopography, hydroperiod, and soil accretion in a deteriorating Louisiana salt marsh. Journal of Coastal Research 11: 357-369.

Cao, H., Z. Zhu, T. Balke, L. Zhang, and T.J. Bouma. 2018. Effects of sediment disturbance regimes on Spartina seedling establishment: implications for salt marsh creation and restoration. Limnology and Oceanography 63: 647-659. https://doi.org/10.1002/lno.10657.

Cao, H., Z. Zhu, R. James, P.M.J. Herman, L. Zhang, L. Yuan, and T.J. Bouma. 2019. Wave effects on seedling establishment of three pioneer marsh species: survival, morphology and biomechanics. Annals of Botany. https://doi.org/10.1093/aob/mcz136.

Carter, C.T., and I.A. Ungar. 2003. Germination response of dimorphic seeds of two halophyte species to environmentally controlled and natural conditions. Canadian Journal of Botany 81: 918-926. https://doi.org/10.1139/B03-086.

Davy, A.J., G.F. Bishop, and C.S.B. Costa. 2001. Salicornia L. (Salicornia pusilla J. Woods, S. ramosissima J. Woods, S. europaea L., S. obscura PW Ball \& Tutin, S. nitens PW Ball \& Tutin, S. fragilis PW Ball \& Tutin and S. dolichostachya Moss). Journal of Ecology 89: 681-707. https://doi.org/10.1046/j.00220477.2001.00607.x.

Davy, A.J., M.J.H. Brown, H.L. Mossman, and A. Grant. 2011. Colonization of a newly developing salt marsh: disentangling independent effects of elevation and redox potential on halophytes. Journal of Ecology 99: 1350-1357. https://doi.org/10.1111/j.13652745.2011.01870.x.

Donat, M.G., D. Renggli, S. Wild, L.V. Alexander, G.C. Leckebusch, and U. Ulbrich. 2011. Reanalysis suggests long-term upward trends in 
European storminess since 1871. Geophysical Research Letters 38. https://doi.org/10.1029/2011g1047995.

Egan, T.P., and I.A. Ungar. 2000. Mortality of the salt marsh species Salicornia europaea and Atriplex prostrata (Chenopodiaceae) in response to inundation. Ohio Journal of Science 100: 24-27.

Elias, E., A. Van der Spek, Z. Wang, and J. De Ronde. 2012. Morphodynamic development and sediment budget of the Dutch Wadden Sea over the last century. Netherlands Journal of Geosciences 91: 293-310. https://doi.org/10.1017/ S0016774600000457.

Ellison, A.M. 1987. Density-dependent dynamics of Salicornia europaea monocultures. Ecology 68: 737-741. https://doi.org/10.2307/ 1938480.

Elsey-Quirk, T., B.A. Middleton, and C.E. Proffitt. 2009. Seed flotation and germination of salt marsh plants: the effects of stratification, salinity, and/or inundation regime. Aquatic Botany 91: 40-46. https://doi.org/10.1016/j.aquabot.2009.02.001.

Erfanzadeh, R., A. Garbutt, J. Petillon, J.P. Maelfait, and M. Hoffmann. 2010a. Factors affecting the success of early salt-marsh colonizers: seed availability rather than site suitability and dispersal traits. Plant Ecology 206 (2): 335-347. https://doi.org/10.1007/s11258-0099646-8.

Erfanzadeh, R., J. Petillon, J.P. Maelfait, and M. Hoffmann. 2010b. Environmental determinism versus biotic stochasticity in the appearance of plant species in salt-marsh succession. Plant Ecology and Evolution 143: 43-50. https://doi.org/10.5091/plecevo.2010.422.

Friess, D.A., K.W. Krauss, E.M. Horstman, T. Balke, T.J. Bouma, D. Galli, and E.L. Webb. 2012. Are all intertidal wetlands naturally created equal? Bottlenecks, thresholds and knowledge gaps to mangrove and saltmarsh ecosystems. Biological Reviews 87 (2): 346366. https://doi.org/10.1111/j.1469-185X.2011.00198.x.

Gedan, K.B., B.R. Silliman, and M.D. Bertness. 2009. Centuries of human-driven change in salt marsh ecosystems. Annual Review of Marine Science 1: 117-141. https://doi.org/10.1146/annurev. marine.010908.163930.

Hacker, S.D., and M.D. Bertness. 1999. Experimental evidence for factors maintaining plant species diversity in a New England salt marsh. Ecology 80: 2064-2073. https://doi.org/10.1890/00129658(1999)080[2064:EEFFMP]2.0.CO;2.

Houwing, E.J. 2000. Morphodynamic development of intertidal mudflats: consequences for the extension of the pioneer zone. Continental Shelf Research 20: 1735-1748. https://doi.org/10. 1016/S0278-4343(00)00045-5.

Hu, Z., W. Lenting, D. van der Wal, and T.J. Bouma. 2015. Continuous monitoring bed level dynamics on an intertidal flat: Introducing novel, stand-alone high-resolution SED-sensors. Geomorphology 223-230. https://doi.org/10.1016/j.geomorph.2015.05.027

Huiskes, A., A. Stienstra, B. Koutstaal, M. Markusse, and J. Van Soelen. 1985. Germination ecology of Salicornia dolichostachya and Salicornia brachystachya. Plant Biology 34: 369-380. https://doi. org/10.1111/j.1438-8677.1985.tb01943.x.

Keiffer, C.H., B.C. McCarthy, and I.A. Ungar. 1994. Effect of salinity and waterlogging on growth and survival of Salicornia europaea L., and inland halophyte. Ohio Journal of Science 94: 70-73. https://doi. org/10.1016/j.pld.2016.06.005.

Khan, M.A., B. Gul, and D.J. Weber. 2000. Germination responses of Salicornia rubra to temperature and salinity. Journal of Arid Environments 45: 207-214.

Kirwan, M.L., S. Temmerman, E.E. Skeehan, G.R. Guntenspergen, and S. Fagherazzi. 2016. Overestimation of marsh vulnerability to sea level rise. Nature Climate Change 6: 253-260. https://doi.org/10. 1038/nclimate2909.

Langlois, E., A. Bonis, and J. Bouzillé. 2001. The response of Puccinellia maritima to burial: a key to understanding its role in salt-marsh dynamics? Journal of Vegetation Science 12: 289-297.
Langlois, E., A. Bonis, and J.B. Bouzille. 2003. Sediment and plant dynamics in saltmarshes pioneer zone: Puccinellia maritima as a key species? Estuarine Coastal and Shelf Science 56: 239-249. https://doi.org/10.1016/s0272-7714(02)00185-3.

Lindig-Cisneros, R., and J.B. Zedler. 2002. Halophyte recruitment in a salt marsh restoration site. Estuaries 25: 1174-1183.

Lo, V.B., T.J. Bourna, J. van Belzen, C. Van Colen, and L. Airoldi. 2017. Interactive effects of vegetation and sediment properties on erosion of salt marshes in the Northern Adriatic Sea. Marine Environmental Research 131: 32-42. https://doi.org/10.1016/j.marenvres.2017.09. 006.

Magnusson, A., H.J. Skaug, A. Nielsen, M.C.W. Berg, K. Kristensen, M. Maechler, K.J. van Bentham, B.M. Bolker, and M.E. Brooks. 2017. glmmTMB: Generalized Linear Mixed Models using Template Model Builder.

Morzaria-Luna, H.N., and J.B. Zedler. 2007. Does seed availability limit plant establishment during salt marsh restoration? Estuaries and Coasts 30 (1): 12-25. https://doi.org/10.1007/bf02782963.

Noe, G.B., and J.B. Zedler. 2001. Variable rainfall limits the germination of upper intertidal marsh plants in Southern California. Estuaries 24: 30-40. https://doi.org/10.2307/1352810.

Olff, H., J. De Leeuw, J.P. Bakker, R.J. Platerink, H.J. Van Wijnen, and W. De Munck. 1997. Vegetation succession and herbivory in a salt marsh: changes induced by sea level rise and silt deposition along an elevational gradient. Journal of Ecology 85: 799-814. https://doi. org/10.2307/2960603.

Petersen, J., B. Kers, and M. Stock. 2014. TMAP-typology of coastal vegetation in the Wadden Sea Area, 1-90. Wilhelmshaven: Common Wadden Sea Secretariat (CWSS).

Pinheiro, J.C., and D.M. Bates. 2000. Linear mixed-effects models: basic concepts and examples. Mixed-effects models in S and S-Plus: 3-56. https://doi.org/10.1007/0-387-22747-4 1 .

Poppema, D.W., P. Willemsen, M.B. de Vries, Z.C. Zhu, B.W. Borsje, and S. Hulscher. 2019. Experiment-supported modelling of salt marsh establishment. Ocean \& Coastal Management 168: 238250. https://doi.org/10.1016/j.ocecoaman.2018.10.039.

R Core Team. 2018. R: A language and environment for statistical computing. Vienna: R Foundation for Statistical Computing.

Rand, T.A. 2000. Seed dispersal, habitat suitability and the distribution of halophytes across a salt marsh tidal gradient. Journal of Ecology 88: 608-621. https://doi.org/10.1046/j.1365-2745.2000.00484.x.

Reise, K., M. Baptist, P. Burbridge, N. Dankers, L. Fischer, B. Flemming, A. Oost, and C. Smit. 2010. The Wadden Sea - a universally outstanding tidal wetland. Wadden Sea ecosystem no. 29, 7-24. Wilhelmshaven: Common Wadden Sea secretariat.

Schuerch, M., T. Dolch, K. Reise, and A.T. Vafeidis. 2014. Unravelling interactions between salt marsh evolution and sedimentary processes in the Wadden Sea (southeastern North Sea). Progress in Physical Geography 38: 691-715. https://doi.org/10.1177/ 0309133314548746.

Schulz, K., and T. Gerkema. 2018. An inversion of the estuarine circulation by sluice water discharge and its impact on suspended sediment transport (vol 200,pg 31, 2018). Estuarine Coastal and Shelf Science 207: 510-510. https://doi.org/10.1016/j.ecss.2018.05.003.

Smit van der Waaij, Y., E.-J. Houwing, W.E.V. Duin, K.S. Dijkema, and J.P.C. Smit. 1995. Salt marshes and sea-level rise: boundary conditions for the growth of Salicornia dolichostachya, 30. Den Burg: IBN - DLO.

Stoddart, D.R., D.J. Reed, and J.R. French. 1989. Understanding saltmarsh accretion, Scolt Head Island, Norfolk, England. Estuaries 12: 228-236. https://doi.org/10.2307/1351902.

Strain, E.M.A., J. van Belzen, P. Comandini, J. Wong, T.J. Bouma, and L. Airoldi. 2017. The role of changing climate in driving the shift from perennial grasses to annual succulents in a Mediterranean saltmarsh. Journal of Ecology 105: 1374-1385. https://doi.org/10.1111/13652745.12799 . 
Temmerman, S., P. Meire, T.J. Bouma, P.M. Herman, T. Ysebaert, and H.J. De Vriend. 2013. Ecosystem-based coastal defence in the face of global change. Nature 504 (7478): 79-83. https://doi.org/10. 1038/nature 12859 .

Ungar, I.A. 1967. Influence of salinity and temperature on seed germination. The Ohio Journal of Science 67: 120-123.

Ungar, I.A. 1978. Halophyte seed germination. The Botanical Review 44: 233-264. https://doi.org/10.1007/BF02919080.

Ungar, I.A. 1987. Population ecology of halophyte seeds. The Botanical Review 53: 301-334. https://doi.org/10.2307/1938462.

van der Wal, D., and P.M. Herman. 2012. Ecosystem engineering effects of Aster tripolium and Salicornia procumbens salt marsh on macrofaunal community structure. Estuaries and Coasts 35 (3): 714-726. https://doi.org/10.1007/s12237-011-9465-8.

van Regteren, M., R. Ten Boer, E.H. Meesters, and A.V. De Groot. 2017. Biogeomorphic impact of oligochaetes (Annelida) on sediment properties and Salicornia spp. seedling establishment. Ecosphere 8: 1-16. https://doi.org/10.1002/ecs2.1872.

van Regteren, M., I. Colosimo, P. de Vries, M.E.B. van Puijenbroek, V.S. Freij, M.J. Baptist, and K. Elschot. 2019. Limited seed retention during winter inhibits vegetation establishment in spring, affecting lateral marsh expansion capacity. Ecology and Evolution 9 (23): 13294-13308. https://doi.org/10.1002/ece3.5781.

Wang, C., and S. Temmerman. 2013. Does biogeomorphic feedback lead to abrupt shifts between alternative landscape states?: An empirical study on intertidal flats and marshes. Journal of Geophysical Research: Earth Surface 118: 229-240. https://doi.org/10.1029/ 2012JF002474.

Wickham, H. 2009. ggplot2: elegant graphics for data analysis. New York: Springer-Verlag. https://doi.org/10.1007/978-0-387-98141-3.

Wickham, H. 2011. The Split-apply-combine strategy for data analysis. Journal of Statistical Software 40: 1-29. https://doi.org/10.18637/ jss.v040.i01.

Widdows, J., N.D. Pope, and M.D. Brinsley. 2008. Effect of Spartina anglica stems on near-bed hydrodynamics, sediment erodability and morphological changes on an intertidal mudflat. Marine Ecology Progress Series 362: 45-57. https://doi.org/10.3354/ meps07448.

Wiehe, P. 1935. A quantitative study of the influence of tide upon populations of Salicornia europea. The Journal of Ecology: 323-333. https://doi.org/10.2307/2256124.
Willemsen, P., B.W. Borsje, S. Hulscher, D. Van der Wal, Z. Zhu, B. Oteman, B. Evans, I. Moller, and T.J. Bouma. 2018. Quantifying bed level change at the transition of tidal flat and salt marsh: can we understand the lateral location of the marsh edge? Journal of Geophysical Research-Earth Surface 123: 2509-2524. https://doi. org/10.1029/2018jf004742.

Willemsen, P.W.J.M., B.W. Borsje, V. Vuik, T.J. Bouma, and S.J.M.H. Hulscher. 2020. Field-based decadal wave attenuating capacity of combined tidal flats and salt marshes. Coastal Engineering 156: 103628. https://doi.org/10.1016/j.coastaleng.2019.103628.

Wolters, M., J.P. Bakker, M.D. Bertness, R.L. Jefferies, and I. Möller. 2005. Saltmarsh erosion and restoration in south-east England: squeezing the evidence requires realignment. Journal of Applied Ecology 42: 844-851. https://doi.org/10.1111/j.1365-2664.2005. 01080.x.

Xie, T., S. Li, B. Cui, J. Bai, Q. Wang, and W. Shi. 2019. Rainfall variation shifts habitat suitability for seedling establishment associated with tidal inundation in salt marshes. Ecological Indicators 98: 694703. https://doi.org/10.1016/j.ecolind.2018.11.056.

Yang, S., B. Shi, T. Bouma, T. Ysebaert, and X. Luo. 2012. Wave attenuation at a salt marsh margin: a case study of an exposed coast on the Yangtze Estuary. Estuaries and Coasts 35: 169-182.

Zedler, J.B., H. Morzaria-Luna, and K. Ward. 2003. The challenge of restoring vegetation on tidal, hypersaline substrates. Plant and Soil 253: 259-273. https://doi.org/10.1023/A:1024599203741.

Zhu, Z., T.J. Bouma, T. Ysebaert, L. Zhang, and P.M. Herman. 2014. Seed arrival and persistence at the tidal mudflat: identifying key processes for pioneer seedling establishment in salt marshes. Marine Ecology Progress Series 513: 97-109. https://doi.org/10. 3354/meps10920.

Zhu, Z., J. van Belzen, T. Hong, T. Kunihiro, T. Ysebaert, P.M. Herman, and T.J. Bouma. 2016. Sprouting as a gardening strategy to obtain superior supplementary food: evidence from a seed-caching marine worm. Ecology 97 (12): 3278-3284. https://doi.org/10.1002/ecy. 1613.

Zuur, A.F., and E.N. Ieno. 2016. A protocol for conducting and presenting results of regression-type analyses. Methods in Ecology and Evolution 7: 636-645. https://doi.org/10.1111/2041-210X.12577.

Zuur, A.F., E.N. Ieno, and C.S. Elphick. 2010. A protocol for data exploration to avoid common statistical problems. Methods in Ecology and Evolution 1: 3-14. https://doi.org/10.1111/j.2041-210X.2009. 00001.x. 